Osteoporosis." Arthritis \& Rheumatology, vol. 69, no. 8, June 2017, pp. 15211537., doi:10.1002/art.40137.

[2] Final Recommendation Statement: Osteoporosis to Prevent Fractures: Screening. U.S. Preventive Services Task Force. July 2019.

Disclosure of Interests: None declared.

DOI: 10.1136/annrheumdis-2021-eular.2583

\section{AB0619 CLINICAL RISK FACTORS, BONE DENSITY AND FALL'S HISTORY AND FRACTURES RELATION: STUDY BY HOSPITAL SURVEY ABOUT 448 CASES}

K. Nassar ${ }^{1}$, S. Janani ${ }^{2} .{ }^{1}$ Ibn Rochd University Hospital, Hassan II University of Medicine and Pharmacy, Rheumatology Department, CASABLANCA, Morocco; ${ }^{2}$ Ibn Rochd University Hospital.. Hassan II University of Medicine and Pharmacy, Rheumatology Department, CASABLANCA, Morocco

Background: Osteoporosis is a disease that affects bone mineral density (BMD) and bone microarchitecture at the origin of an increased risk of fracture. The reduction in bone density assessed by dual-energy $X$ ray absorptiometry (DXA) and fall history represent the first two risk factors of non-vertebral fracture after menopause. Given the high prevalence of osteoporosis among fallers subjects with common risk factors, causing a surisk of fracture. Several publications including the osteoporosis recommendations indicate DXA in women experienced falls in search of bone fragility may justify a treatment for osteoporosis, especially as the FRAX tool does not include at present the fall of history, an important parameter in the assessment of fracture risk.

Objectives: Because of the low attention given to the evaluation of falls'risk, the main objective of the study was to determine the prevalence and the relationship between the past history of fall, reduction of bone mineral density and prevalent fracture.

Methods: Transversal and descriptive epidemiological cohort study conducted for 24 months in 448 patients referred by physicians regularly use prescription of BMD. The realization of this exploration by the same DXA-Hologic in the rheumatology department at Ibn Rochd University Hospital was the criterion for entry into the study. All patients were interviewed on the same day on the risk factors for osteoporosis and fractures justifying the prescription of a BMD.

Results: Data included 413 women and 35 men. Most women were postmenopausal $(89.6 \%)$. The average age was 59 years $(\sigma=13.40)$, $33.7 \%$ were $\geq 65$ years. The mean BMI was at $27.50(\sigma=5,2) .18 .5 \%$ of patients had at least a history of falls in the previous 12 months and $22.5 \%$ a history of fracture after a low-energy trauma. $42.9 \%$ were osteoporotic and $57.1 \%$ had osteopenia in at least one of these sites: lumbar spine, femoral neck, total hip. We did not find significant association between BMD osteoporosis and fall history $(p=0.916)$. Thus, cases of osteoporosis fractures were not statistically associated with a fall $(p=0.170)$. Also, the falls were occurring than $18.4 \%$ of osteopenic patients $(p=0.220)$. However, in our study, the fall was an independent risk factor for fracture $(p=0.003)$ and osteopenic fractures were significantly higher among fallers $(p=0.009$ and 0.006 respectively, a drop of history and at least one past fall history).

Conclusion: The fall history is a independent risk factor for fracture. This risk is particularly important in case of fragility bone densitometry. The clinical history and fall risk factors should be taken into consideration in the assessment of fracture risk and in the anti-ostoporotique treatment strategy. Thus, the fall seems to be a legitimate indication for DXA and as a parameter to be integrated into the assessment of fracture risk by the FRAX score.

REFERENCES:

[1] MH. Edwards, K. Jameson, H. Denison, NC. Harvey, Sayer A. Aihie, EM Dennison, and C Cooper. Clinical risk factors, bone density and fall history in the predection of incident fracture among men and women. Bone. 2013; 52(2): 541-547.

Table 1. Multivariate Logistic Regression Results: Adjustment for predictors factors of falls

\begin{tabular}{lcc}
\hline Variables & OR (95\% IC) & p-value \\
\hline Age $\geq 65$ ans & $0,986(0,412-2,357)$ & 0,974 \\
Past history of fracture & $4,271(1,719-10,611)$ & 0,02 \\
Walking aid & $11,214(2,815-44,670)$ & 0,01 \\
Vision disturbances & $8,587(3,540-20,829)$ & $<0,001$ \\
Rhumatoid arthritis & $8,047(2,218-29,192)$ & 0,02 \\
Diabete & $3,194(1,217-8,382)$ & 0,018 \\
Corticosteroid $\geq 3$ mois & $0,603(0,156-2,331)$ & 0,463 \\
Smoking & $0,241(0,013-4,518)$ & 0,341 \\
Ostéopenia $(-1 \leq$ T-score $<-2,5)$ & $2,204(0,875-5,552)$ & 0,094 \\
\hline
\end{tabular}

Disclosure of Interests: None declared.

DOI: 10.1136/annrheumdis-2021-eular.2705

\begin{tabular}{l|l}
\hline AB0620 & MODIFICATION OF THE DECISION OF THE ANTI- \\
OSTEOPOROSIS TREATMENT AFTER PERFORMING \\
THE VFA
\end{tabular}

H. Tantaoui ${ }^{1}$, K. Nassar ${ }^{1}$, S. Janani ${ }^{1} .{ }^{1}$ Faculty of Medicine and Pharmacy, Hassan II University, Ibn Rochd University Hospital Center, Rheumatology, Casablanca, Morocco

Background: Spinal fractures are the most common of all osteoporotic fractures. Its diagnosis is essential, because the discovery of a vertebral fracture testifies the gravity of osteoporosis and modifies the therapeutic intervention threshold by justifying a specific anti-osteoporosis treatment. The evolution of densitometers now makes it possible to take a true X-ray image using software called "Vertebral Fracture Assessment" or VFA

Objectives: To assess the impact of VFA results on therapeutic decision-making after measuring bone mineral density.

Methods: We conducted a retrospective and descriptive study in the rheumatology department.

We included all patient followed at the consultation for bone pathologies, in whom a measurement of bone mineral density and a supplementation of VFA were performed. Clinical data, BMD, VFA and the therapeutic decision by anti-osteoporosis treatment before and after VFA were collected.

Results: Sixty-one patients were included. The mean age was 62.8 years [38 - 85 years]. Sex ratio (female / male) was 19.3. At BMD level, patients with osteoporosis and osteopenia were $49 \%$ and $51 \%$ respectively. VFA objectified at leas one spinal fracture in $64 \%$ of patients. Prior to VFA, anti-osteoporosis therapy was indicated to $49 \%$ of patients, based on clinical data and BMD. After performing VFA, the prescription of anti-osteoporosis therapy was indicated to $80 \%$ of patients.

Conclusion: Patients who had no indication for osteoporosis treatment based on BMD data, VFA was able to modify their therapeutic treatment by detecting vertebral fractures in patients who had back pain.

Disclosure of Interests: None declared.

DOI: 10.1136/annrheumdis-2021-eular.3318

\section{$\mathrm{AB} 0621$ \\ THE MAIN CAUSES OF MORTALITY IN PATIENTS WITH OSTEOPOROTIC HIP FRACTURES}

J. Averkieva ${ }^{1}$, M. Letaeva ${ }^{1}$, O. Malyshenko', M. Koroleva ${ }^{1}$, T. Raskina ${ }^{1}$.

${ }^{1}$ Kemerovo State Medical University, Department of Propedeutics of Internal Medicine, Kemerovo, Russian Federation

Background: Increasing life expectancy is one of the main achievements of modern medicine. However, longevity is inevitably associated with the growth of so-called "age-associated diseases," among which osteoporosis occupies an important place.

Objectives: To study the causes of mortality in patients with hip osteoporotic fractures during 12 months after injury.

Methods: Traced the causes of mortality 432 patients with osteoporotic hip fractures were under observation: 328 women and 104 men. The mean age of women was $75.4 \pm 9.27$ years, the mean age of men was $71.5 \pm 10.39$ years.

Results: This study traced the causes of deaths by the main classes of ICD10. It was found that 6 months after a hip fracture in $63(66.3 \%)$ patients, death occurred from diseases of the circulatory system: in men - 13 (59.0\%) cases and in women - $50(68.4 \%)(p=0.9)$. Respiratory diseases, as a cause of death were identified in $18(18.9 \%)$ patients (in men - $5(22.9 \%)$ cases and in women - $13(17.8 \%)(p=0.1))$, neoplasms - in $10(10.5 \%)$ men and women: $2(9.1 \%)$ and $8(10.9 \%)$ cases, respectively $(p=0.5)$. Diseases of the digestive system accounted for a small percentage of the total number of deaths $(3.2 \%)$, without statistically significant differences by gender (in men - $1(4.5 \%)$ case and in women $-2(2.9 \%)$ cases $(p=0.75))$. Among the dead men, $1(1.1 \%)$ death from an infectious disease was registered. 12 months after the fracture, most of the deaths in both men and women were due to diseases of the circulatory system. The total number of deaths was $93(67.8 \%)$ : in men - 22 (66.0\%) cases, in women - $71(68.3 \%)(p=0.65)$. Respiratory diseases caused death in 23 $(16.8 \%)$ patients: in men $-5(15.1 \%)$ cases and in women - $18(17.3 \%)(p=0.31)$ There is an increase in the number of deaths from neoplasms to $15(10.9 \%)$ cases without statistically significant differences by gender: in men - $3(9.09 \%)$ cases and in women - $12(11.5 \%)(p=0,45)$. Diseases of the digestive system, as a cause of death, were identified in $5(3.6 \%)$ men and women $(2(6.06 \%)$ and $3(2.9 \%)$ cases, respectively $(p=0.1))$. No new cases of deaths from infectious diseases were registered. 